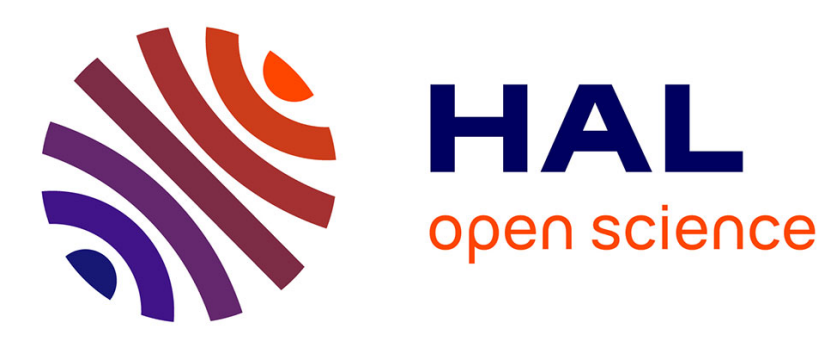

\title{
Numerical simulations of energy transfer in counter-streaming plasmas
}

M Hadj-Bachir, R Capdessus, Vladimir Tikhonchuk, Emmanuel d'Humìeres

\section{To cite this version:}

M Hadj-Bachir, R Capdessus, Vladimir Tikhonchuk, Emmanuel d'Humì̀res. Numerical simulations of energy transfer in counter-streaming plasmas. Summer school in the frame of ERASMUS IP "An Introduction to high power light-matter interactions (HIPOLIN 2013)", Jul 2013, Crete Greece. hal01332843

\section{HAL Id: hal-01332843 \\ https://hal.science/hal-01332843}

Submitted on 16 Jun 2016

HAL is a multi-disciplinary open access archive for the deposit and dissemination of scientific research documents, whether they are published or not. The documents may come from teaching and research institutions in France or abroad, or from public or private research centers.
L'archive ouverte pluridisciplinaire HAL, est destinée au dépôt et à la diffusion de documents scientifiques de niveau recherche, publiés ou non, émanant des établissements d'enseignement et de recherche français ou étrangers, des laboratoires publics ou privés. 


\section{Numerical simulations of energy transfer in counter-streaming plasmas}

\section{HADJ-BACHIR}

CELIA

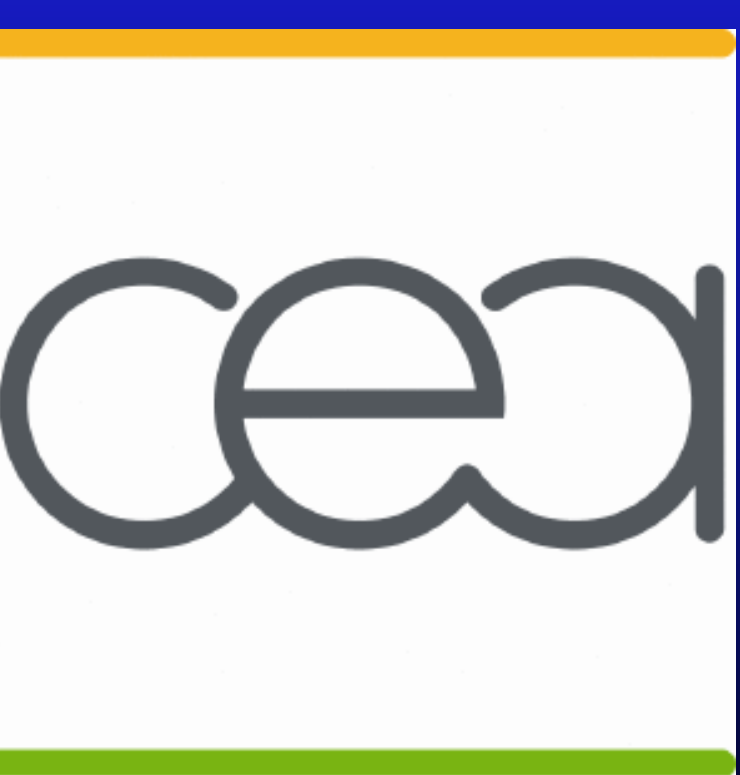

Supervisors: R. CAPDESSUS, E. d'HUMMIERES, V. T. TIKHONCHUK Univ.Bordeaux, CEA, CNRS , CELIA, 33405 Talence France.

Email: hadjbachir@celia.u-bordeaux1.fr
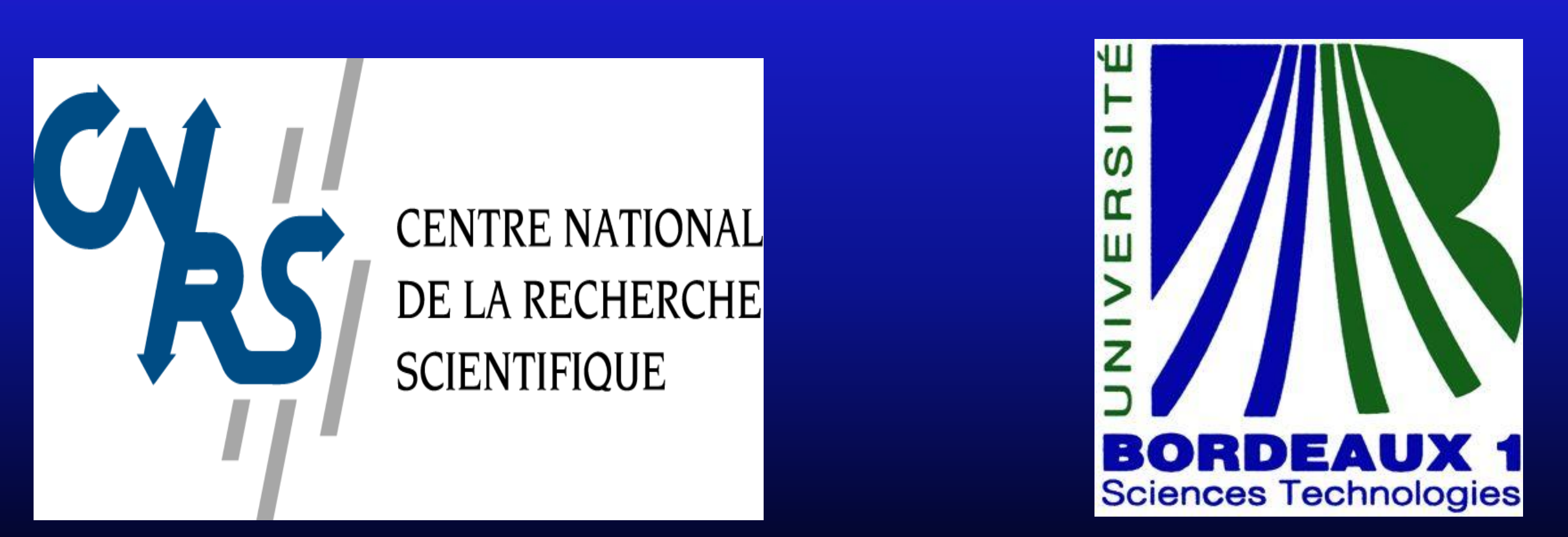

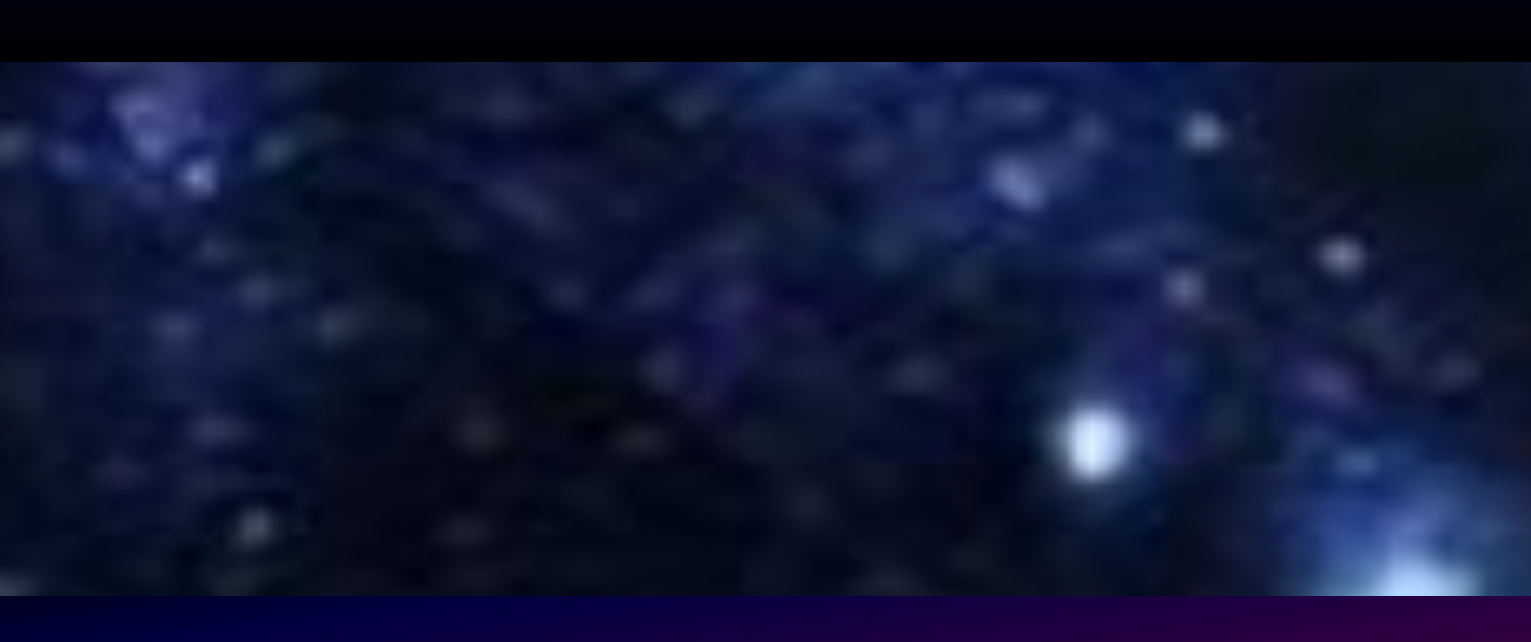

Introduction

Collisiontess shocks are They transform energy of star explosion into hot plasma that the Weibel instability is a very good candidate to explain GRBs [7]. We demonstrate with particule-in-cel simulations that a part of directed kinetic energy of proton beams is converted into energy of electron, ions, electit energetics of flow and we demonstrate that clechon heating is an important catalyst to shock formation vit filamentation instability [3], [4].

Colliding plasmas in universe.

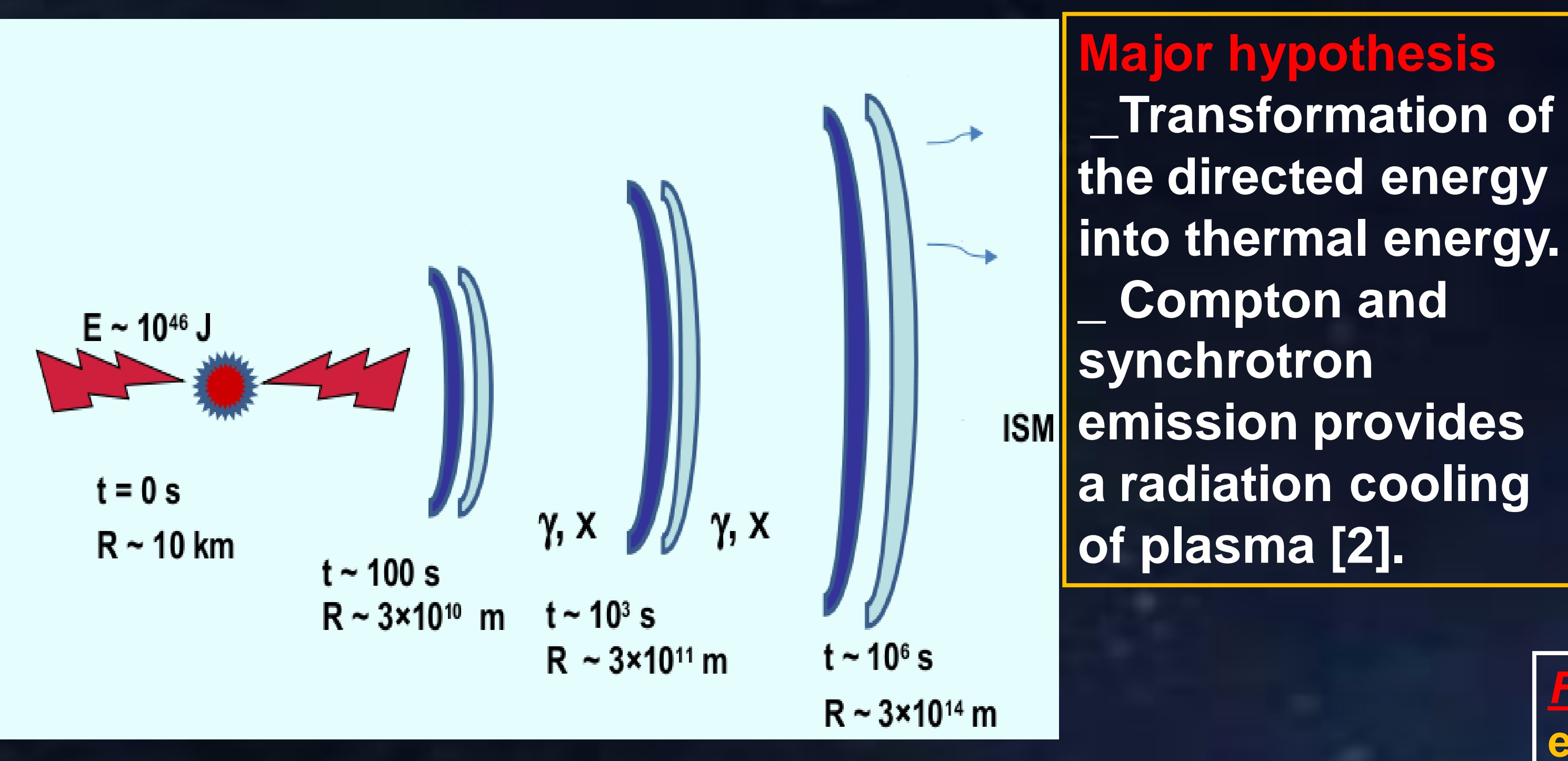

-jecta from the central explosion : hot plasma. interaction with the ISM cold plasma. explains the shor
ers [2],44]. pulse duration recorded by observers [2], [4]

Modeling shocks in astrophysical laboratories

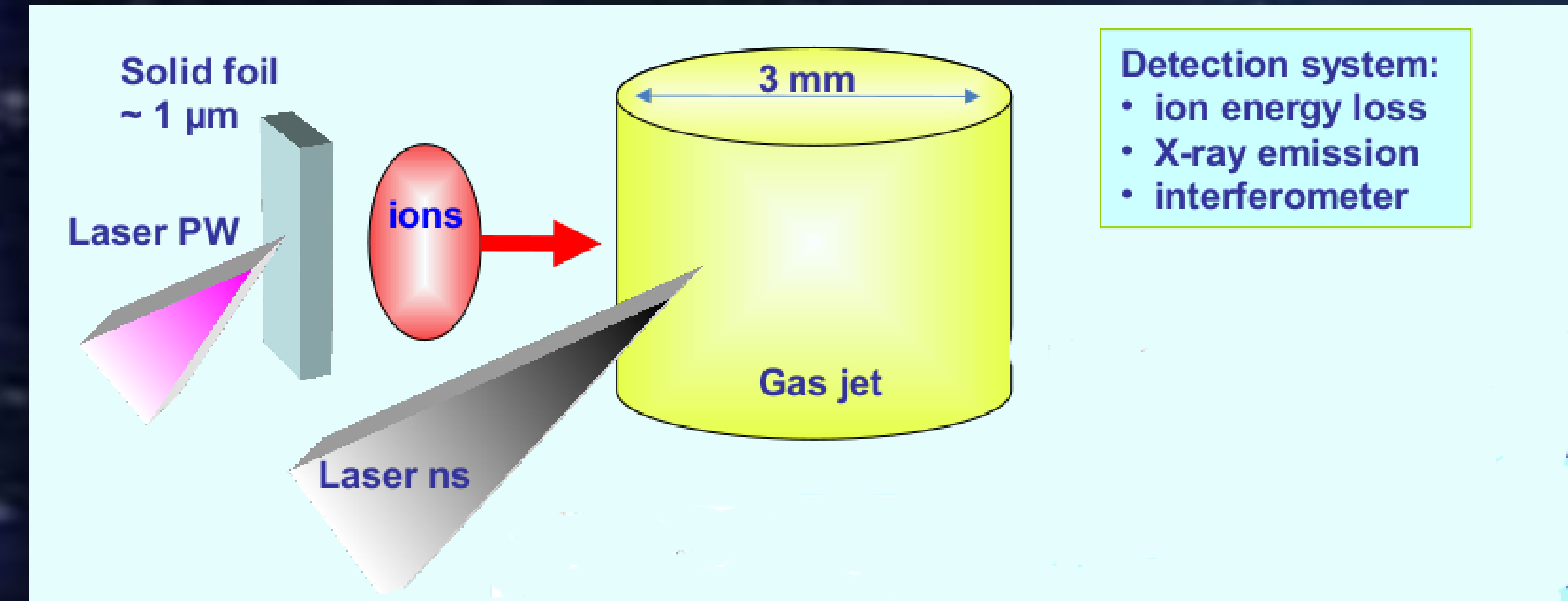
Scheme of laboratory experiment on the collisionles:
dissipation of fast ion beams [1].

1.A proton bunch
short laser pulse.

2 _Transport zone of the proton bunch to the interaction site. 3_ Target plasma created by ionization of a gas jet with an auxiliary lase 4- Di
PIC simulations of sub-relativistic plasmas

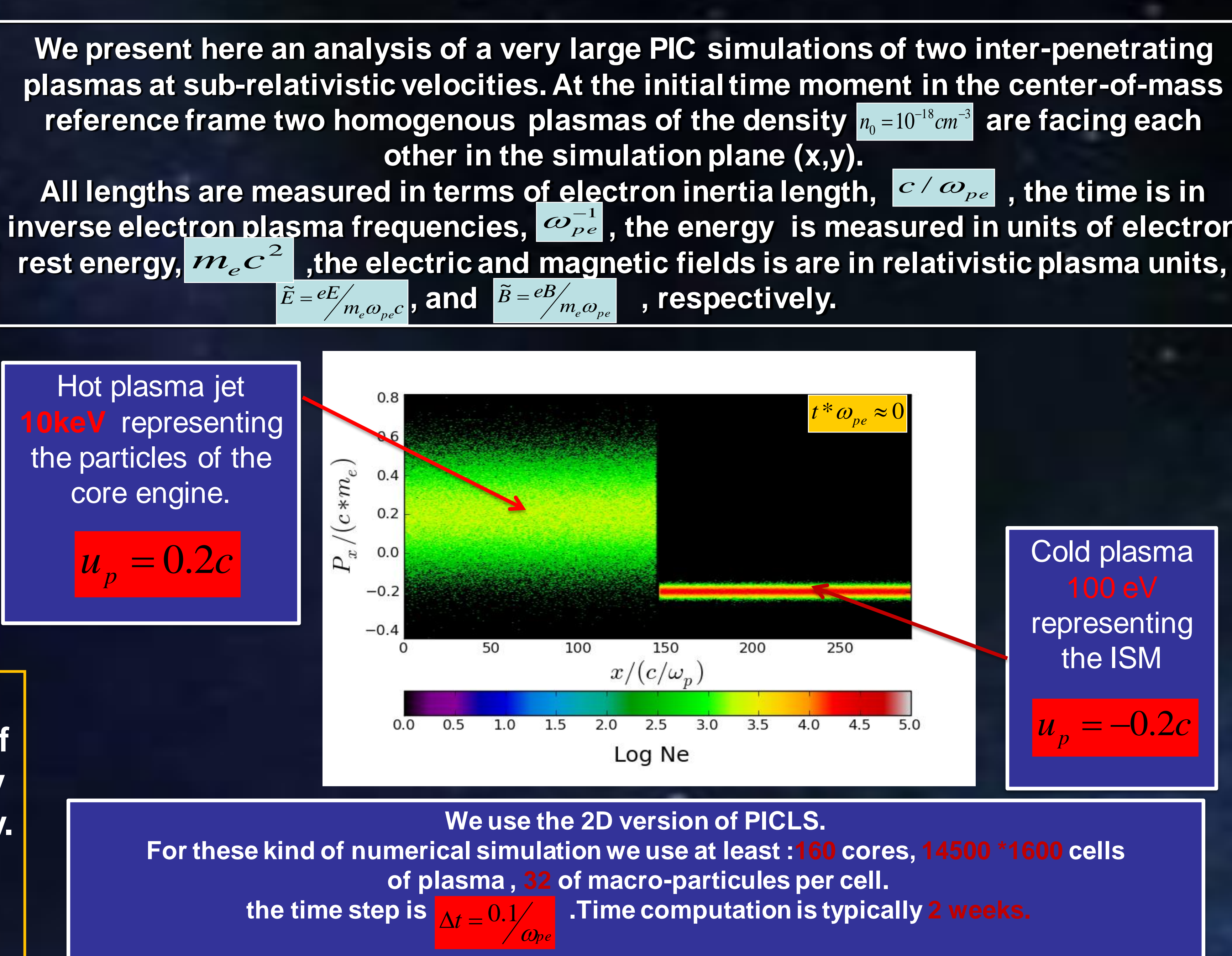

Temporal development of inter-penetrating plasmas
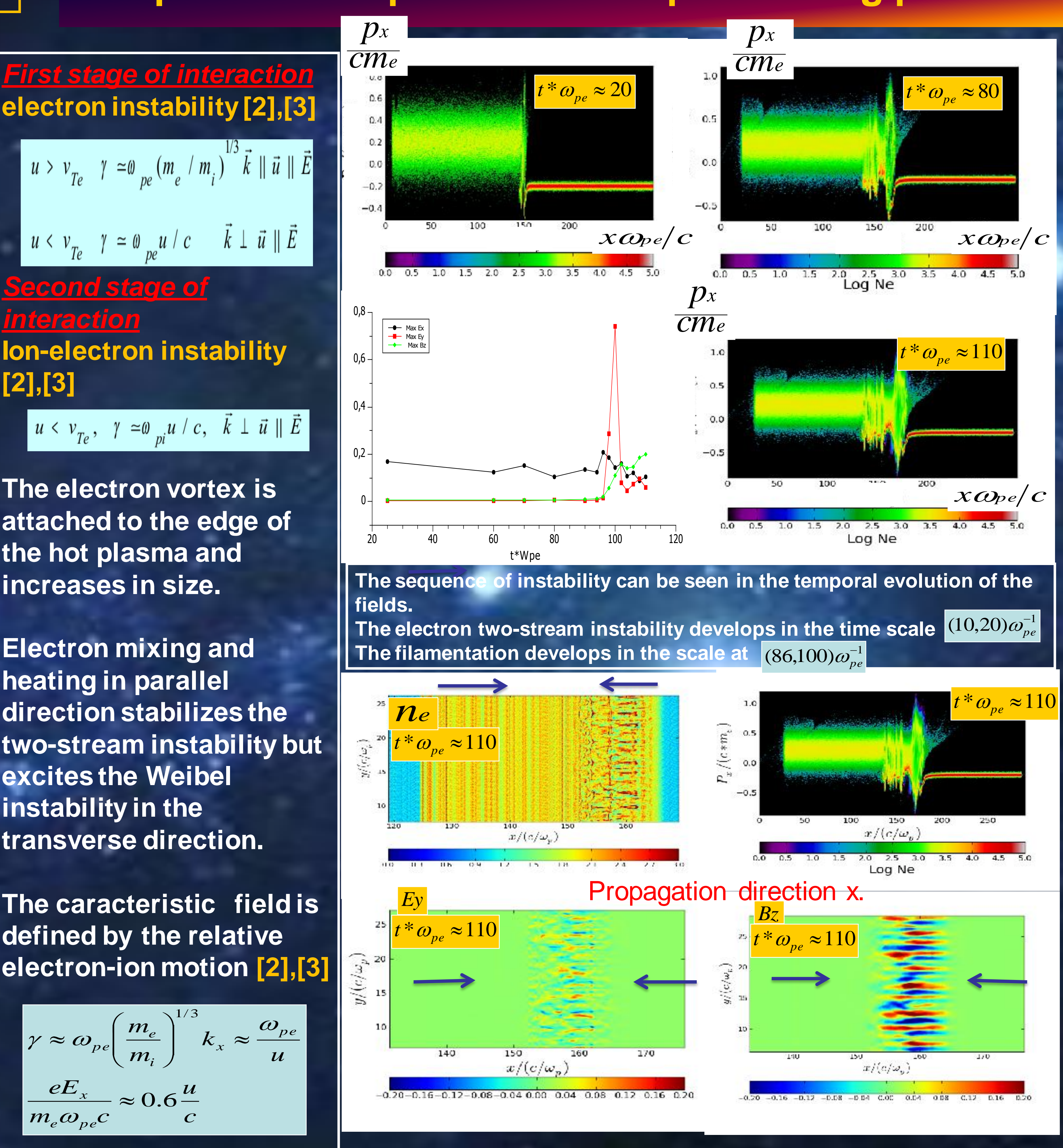

Distribution functions of the electrons. Asymetric case $10 \mathrm{keV} / 100 \mathrm{eV}$

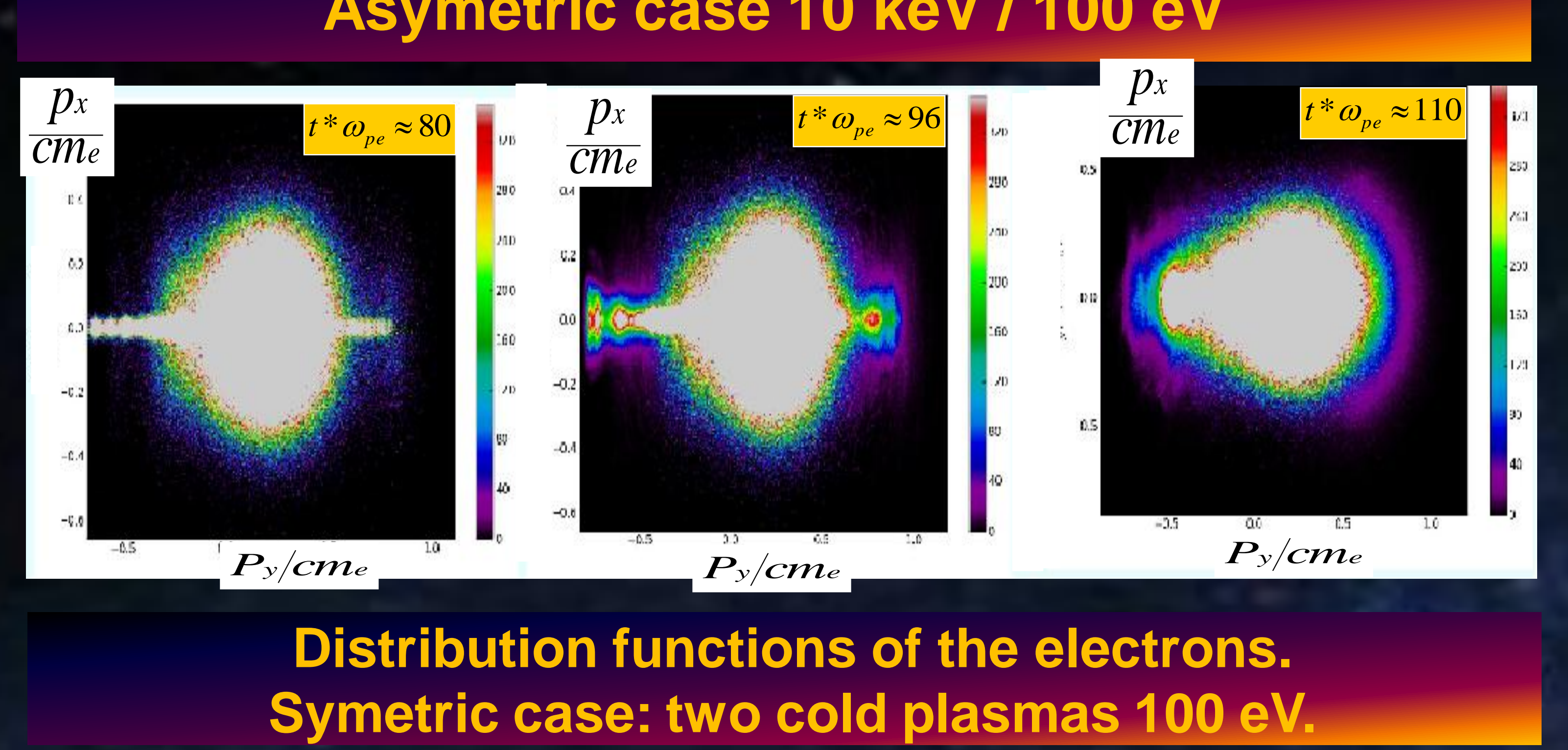

Distribution functions of the electrons.
Symetric case: two cold plasmas $100 \mathrm{eV}$.

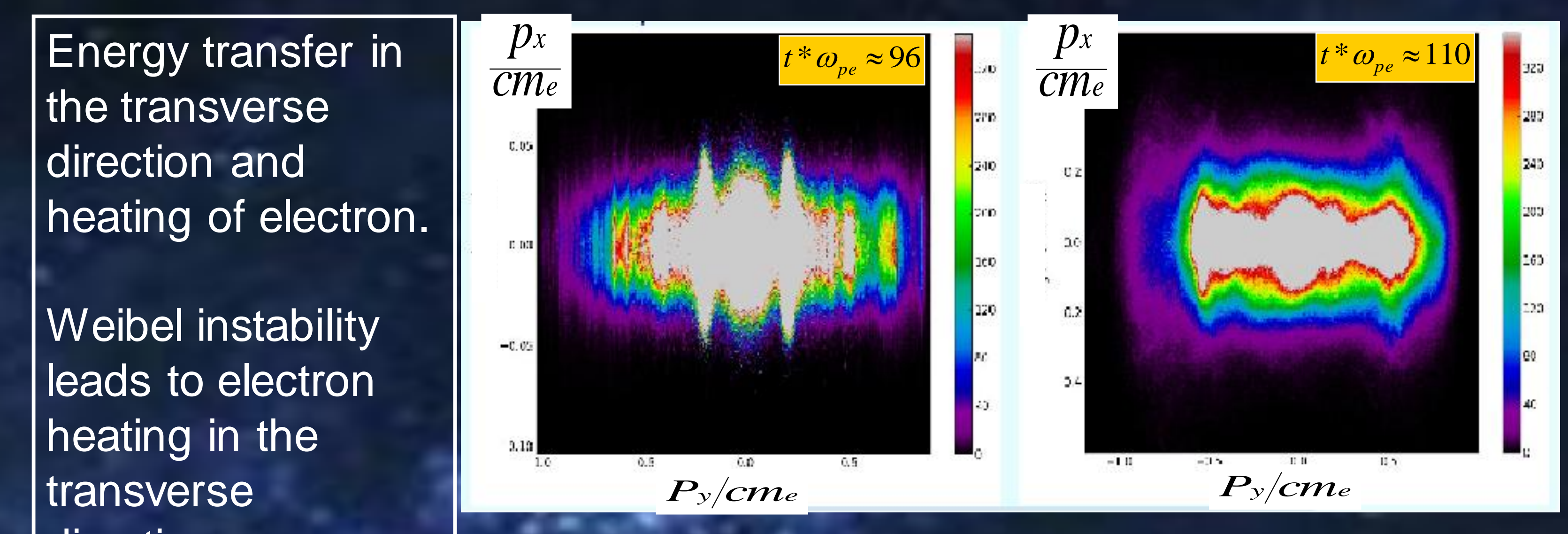

transverse
direction.
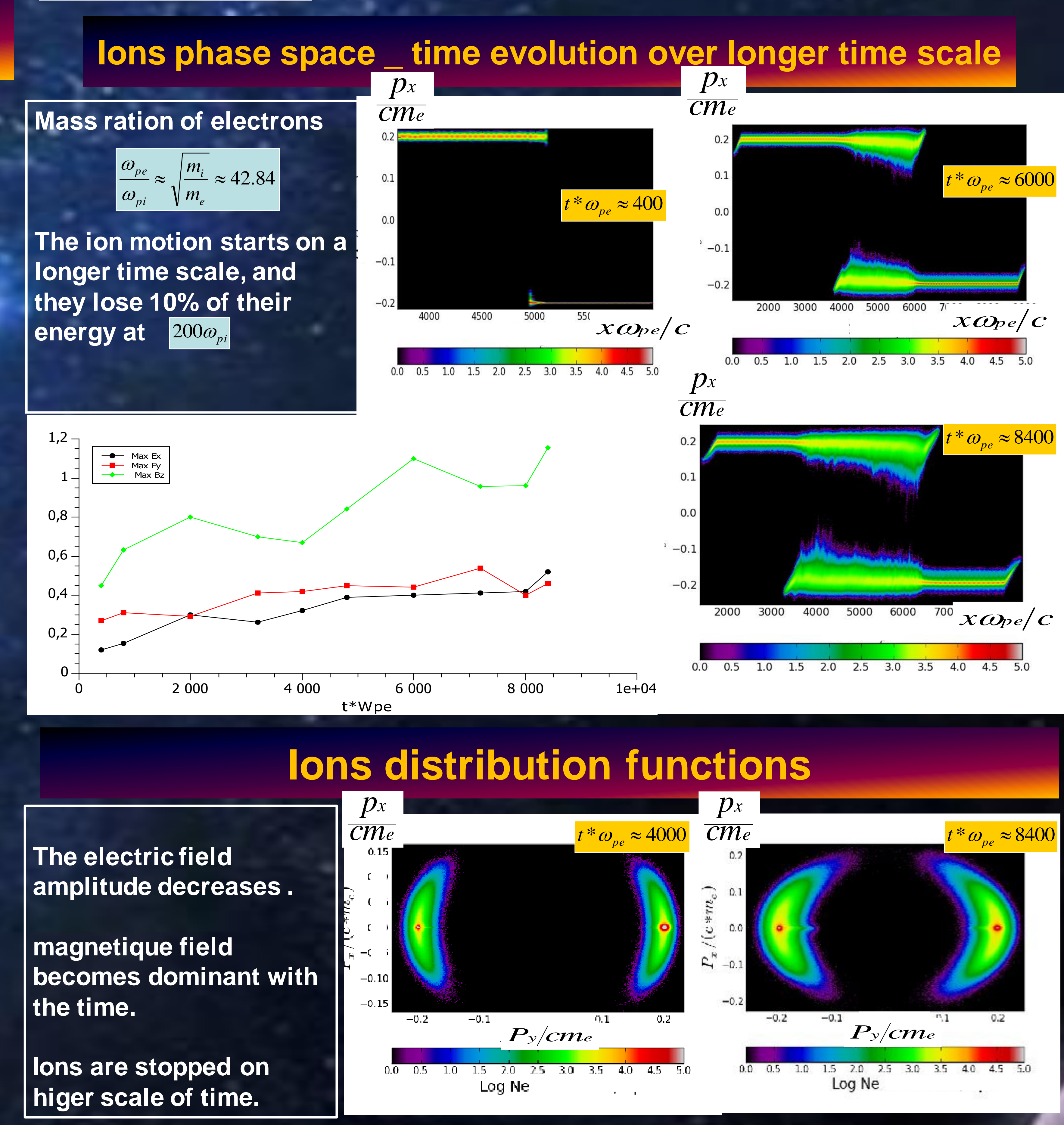

Evolution of filaments
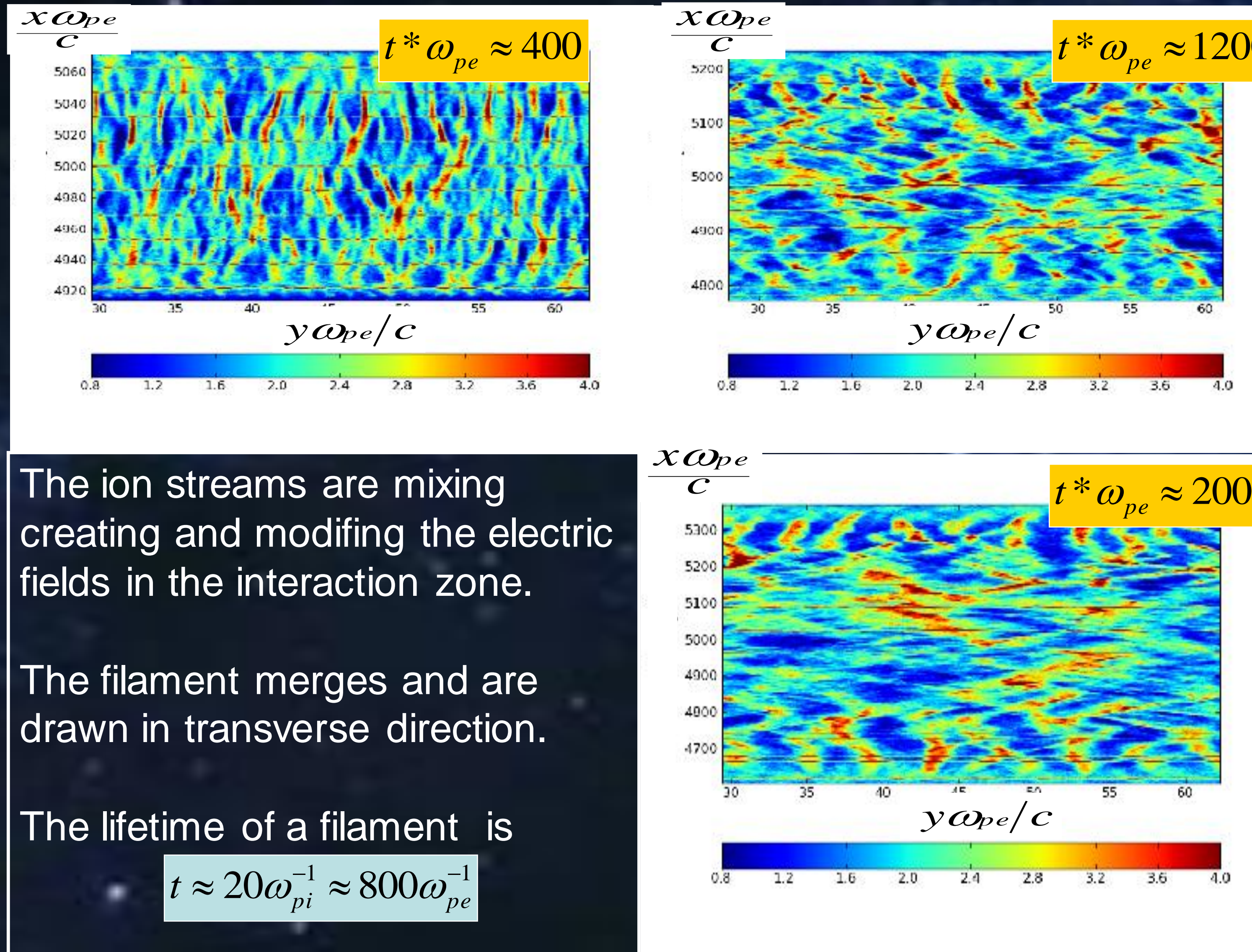

Very high energy of electrons in the filament.

Strong electrostatic field due to the charge separation.

Conclusion

An experiment for studying the collisionelss mechanissm of tast ion energy in laboratery plasmanais propossed. We electron-ion sub-relativisitic counter-streaming plasma beams propagating without an external magnetic field. Electron heating is an important stage of shock formation.
This is probably due to stochastic processes that occurs due to the strong charge separation. Radiation emission losses is due to electron synchrotron emission [7]. Simulations of similar physical processes at the GRB scale References

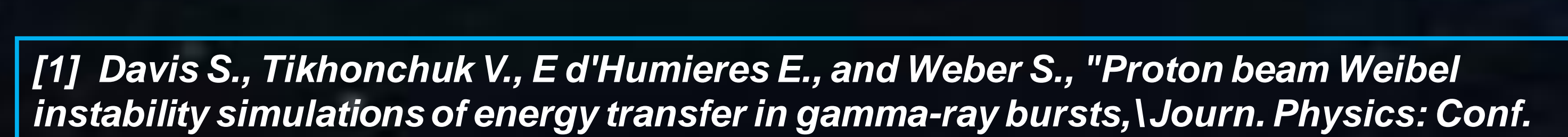

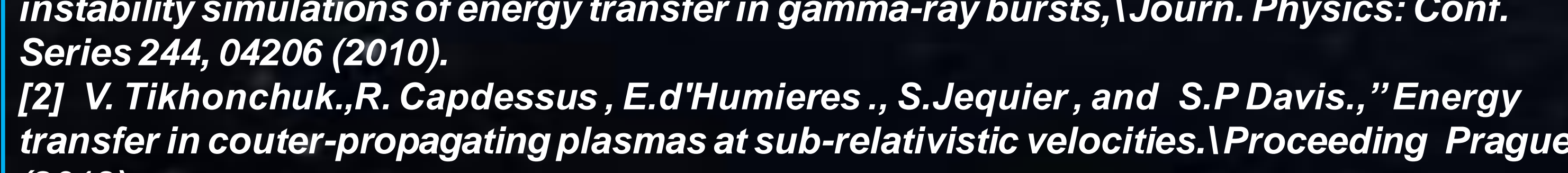

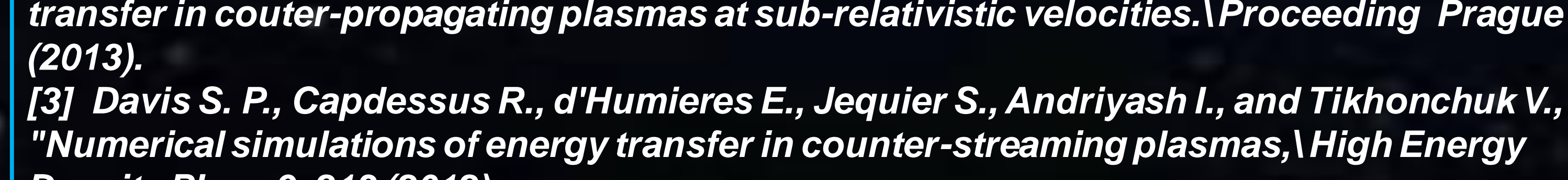
Numerical simulations of energ
Density Phys. $, 2,21$ (2012).

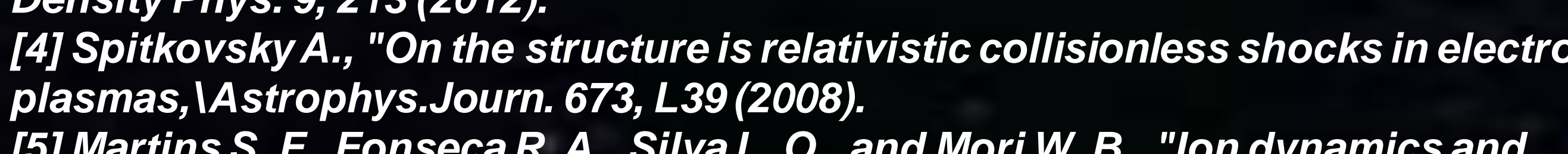

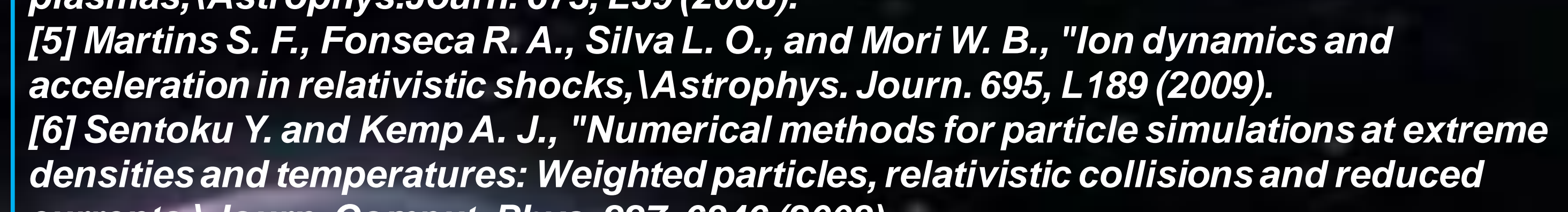

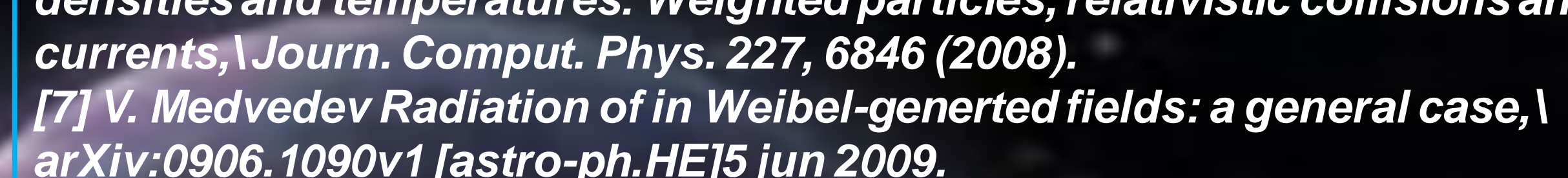

